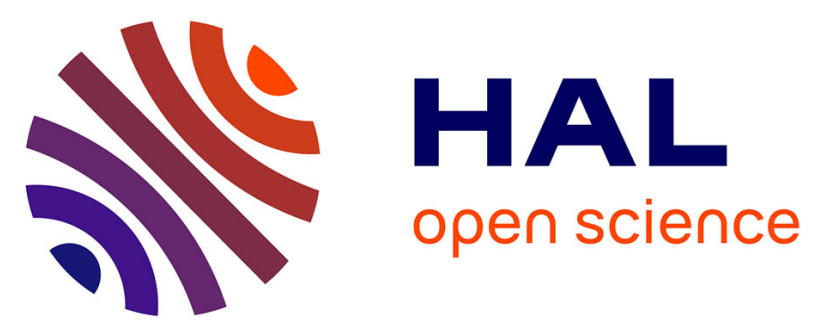

\title{
A Model for Developing Usable Integrated Case Management Information Systems
}

Edgar Kuhimbisa, Rehema Baguma, Agnes Nakakawa

\section{To cite this version:}

Edgar Kuhimbisa, Rehema Baguma, Agnes Nakakawa. A Model for Developing Usable Integrated Case Management Information Systems. 14th International Conference on Social Implications of Computers in Developing Countries (ICT4D), May 2017, Yogyakarta, Indonesia. pp.617-628, 10.1007/9783-319-59111-7_50 . hal-01650084

\section{HAL Id: hal-01650084 \\ https://hal.inria.fr/hal-01650084}

Submitted on 28 Nov 2017

HAL is a multi-disciplinary open access archive for the deposit and dissemination of scientific research documents, whether they are published or not. The documents may come from teaching and research institutions in France or abroad, or from public or private research centers.
L'archive ouverte pluridisciplinaire HAL, est destinée au dépôt et à la diffusion de documents scientifiques de niveau recherche, publiés ou non, émanant des établissements d'enseignement et de recherche français ou étrangers, des laboratoires publics ou privés. 


\title{
A Model for Developing Usable Integrated Case Management Information Systems
}

\author{
Edgar Kuhimbisa $^{1}$, Rehema Baguma ${ }^{2}$ and Agnes Nakakawa ${ }^{3}$ \\ ${ }^{1}$ College of Computing and Information Sciences, Makerere University, Kampala, Uganda \\ edgarkuhimbisa@gmail.com \\ ${ }^{2}$ College of Computing and Information Sciences, Makerere University, Kampala, Uganda \\ rehema.baguma@gmail.com \\ ${ }^{3}$ College of Computing and Information Sciences, Makerere University, Kampala, Uganda \\ agnesnakakawa@gmail.com
}

\begin{abstract}
The increased adoption of technology in government-driven processes and services over the years has led to the use of information and communication technologies (ICTs) as mechanisms and platforms for citizens to access justice services and participate in the judicial process. In Uganda, there are current and ongoing efforts, through e-justice initiatives in the Justice, Law and Order Sector, to integrate case management information systems in criminal justice institutions as a means of improving worker productivity, facilitating information sharing, collaboration, better information access by the general public, citizen engagement and satisfaction with public services. The focus for this study was to devise a model that provides guidance on how to develop integrated information systems that are usable - by supporting improved human-driven legal processes, increased citizen engagement and facilitation of interaction between justice agencies and the general public. Based on the requirements for usable integrated information systems obtained from the review of literature and a survey, a model for guiding development of usable integrated case management information systems known as the Architecture-driven Usability Process Model (AdUPRO) was created.
\end{abstract}

Keywords. Usability, Integrated Information Systems, Case Management, EJustice

\section{INTRODUCTION}

Uganda's Justice, Law and Order Sector (JLOS) is a collection of government institutions with shared and closely linked mandates of administering justice, maintaining law and order and human rights. Whereas JLOS program reforms are credited with improved access to justice, there still exist systemic challenges in ensuring access to justice for all Ugandans especially for the poor and marginalized persons [10]. The lack of well designed, effective and efficient case management information systems 
has been identified as one of the bottlenecks in the delivery of justice in Uganda characterized by challenges in reporting crimes by the public, tracking cases, citizen participation in court processes, management of suspects and allocation of human and financial resources [10]. Where information systems exist in Uganda's criminal justice system, these (systems) were originally designed to function within individual institutional contexts with minimal or no interface with systems in other institutions. Furthermore, most of these systems were acquired off-the-shelf and they are mainly used for data capture with little or no support for dissemination of information and user interaction. This lack of effective mechanisms for interaction and engagement disempowers members of the public who are participants in the justice process as victims of crime, accused parties, court litigants, private counsel and members of the jury.

Systems integration in the justice sector can be viewed as a step towards "ICT4D 2.0" where new e-governance realities are created through more information intensive processes, information sharing, collaboration, increased user engagement and participation in the justice due process. This e-governance paradigm facilitated by integration of information spaces leads to "i-governance" - which according to Heeks [8] integrates people, processes, information and technology in the service of achieving governance objectives. However, the systems integration process results into a union of different processes, end users, corporate cultures and diverse information behaviors [3]. This environment of diversity presents a critical usability challenge that may ultimately contribute to the failure e-governance projects. The recommendation therefore, is that technology implementations should not undermine but rather accommodate this diversity [14].

ISO defines usability as "the extent to which a product can be used by specified users to achieve specified goals with effectiveness, efficiency, and satisfaction in a specified context of use" [11]. Therefore for the integrated information system for Uganda's Justice, Law and Order Sector to achieve its intended objectives, it must be usable - designed to consider various usability aspects such as users of the system (considering their behavioral characteristics, cognitive abilities and conative tendencies), tasks and roles, business processes, goals of the users and an understanding of the dynamic contexts in which the (integrated) information system will be used [6,7].

However, there is still lack of an appropriate approach for analyzing and incorporating the dynamic and often complex usability aspects in the design of integrated information systems. Existing models do not provide adequate guidance on how to achieve usability in the development of integrated information systems. Hence, there is need for more research about how usability issues of integrated information systems can be addressed. This study examines how the usability aspects of integrated information systems can be addressed in the process of developing integrated information systems that are a must have in certain settings such as the Justice, Law and Order sector in Uganda. The next section presents the methodology that was used to address the objectives of this study.

\section{METHODOLOGY}

To achieve the objectives of this study i.e. to collect requirements for usable integrated information systems; and to design a model for developing usable integrated 
criminal case management information systems, the following methodology was followed: For the first objective, the study used review of related literature from journals, book chapters, conference proceedings and a survey to establish usability requirements for integrated information systems. The aim of literature review was to establish what related research studies have given as usability requirements for integrated information systems. On the other hand, the survey was aimed at establishing the usability needs for an integrated case management information system in Uganda and ways such needs can be met from public officials in the four JLOS institutions studied i.e. the Uganda Police, Directorate of Public Prosecutions (DPP), the Judiciary and the Uganda Prisons Services. These institutions are representative of the case management process in the criminal justice system in the country.

Other respondents in this survey were drawn from members of the general public and practicing private lawyers. Members of the general public that participated in the survey were those that regularly interact with the Police, DPP, Judiciary and the Uganda Prisons Services through requests for information and services.

Selection of respondents was based on participants' level of knowledge and insight into how the justice system operates based on previous verified experience. This sampling technique was vital in order to obtain first hand information about the usability needs, information collected, stored and used in the Justice, Law and Order Sector.

Eighty-five (85) officials from the Uganda Police, DPP, Judiciary and Uganda Prisons Service (state actors) participated in the survey. These included: Uganda Police (06 Criminal Intelligence and Investigation Department Officers, 05 Data Managers, 06 Records Clerks / Officers (02), Forensic Officers; 01 Public Relations Officer); Directorate of Public Prosecutions (08 State Attorneys, 01 Client Relations Officer, 05 Records Clerks, 04 Data /Information Managers; Judiciary (04 Judges, 07 Magistrates, 05 Data / Information Managers, 06 Records Clerks /Officers, 02 Public Relations Officers); Uganda Prisons (06 Prison Warders, 07 Facility administrators (Officers-in-Charge), 05 Records Clerks/Officers, 04 Data/Information Managers, 01 Public Relations Officer).

Fifteen (15) members of the public - seven males and eight females, with a history of interaction with the criminal justice system were selected to participate in the survey. Ten (10) private lawyers that interact with the criminal justice system through legal representation of members of the general public during the litigation process were selected to also participate in the study.

A self-administered questionnaire was chosen as an appropriate data collection tool for public officials because it facilitated gathering of a significant number of responses from a large sample of respondents in a relatively short period of time. An interview guide was deemed suitable for gathering responses from the general public and private legal practitioners due to its ability to gather detailed responses (opinions and perceptions).

Requirements gathered from the questionnaire, interviews and review of related literature were used to design a model known as the Architecture-driven Usability Process Model (AdUPRO) that provides guidance on how to design usable integrated information systems. The next section presents findings from the study. 


\section{FINDINGS}

This section presents usability requirements for integrated information systems gathered from the review of related literature, and the survey.

\section{Information presentation is critical for decision-making.}

Information presentation is the use of computer-supported interactive visual representation of abstract data to amplify cognition [4]. According to Dykes et al [5], information presentation aims at providing graphical presentations and user interfaces for interactively manipulating information items. Integrated information systems should therefore be able to provide a mechanism for providing appropriate presentation of processed data from the various institutions into well-aggregated facts for users to derive meaning and use as a basis for decision-making.

\section{Early focus on users is a critical design success factor.}

Understanding user needs is a necessary condition for designing a system that users can integrate into their work and which reflects their worldview [14]. Participation of the public (citizens) in e-government processes is identified as a critical success factor where public decisions are responsive to citizen's views or needs [8]. Therefore, involving the public in the systems design process ensures that their views and perspectives on the usability of technology (integrated information systems in case management) are taken seriously and adhered to as critical.

\section{Iterative Design}

Iterative design relates to being able to continuously modify a system as per the testable behavioral goals and available user feedback till the system is deemed usable. However, iterations to design are often ignored because they make the entire process of systems development a long and expensive venture [12]. According to Gould and Lewis [7], iterative design should not be viewed as a luxury tuning method that puts finishing touches on a design but rather as a way of confronting the design actuality of unpredictable user needs and behaviors that can lead to sweeping and fundamental changes in the design.

\section{Information Systems currently used by JLOS Institutions.}

The four (4) institutions surveyed use different types of information systems each tailored to the agency's mandate and information needs. The Crime Records Management System (CRMS) in the Uganda Police supports the day-to-day transactions of crime records management at police stations; the Prosecutions Case Management System (PROCAMS) in the office of the DPP provides overall management of case files management by the prosecutions offices; the Court Case Management System (CCAS) in the Judiciary is customized software for managing case records-with both civil and criminal case management modules; and the Prisons Information Management System (PIMS) manages prisons data on inmates and prison facilities across the country. Although all JLOS institutions currently have information systems in some form, they are still stand-alone. Therefore, there is a need for an integrated information 
system that the four (4) institutions can jointly use and leverage for collaboration, information sharing and engagement with the public in the provision of services.

\section{Levels of Proficiency with Information Communication Technology.}

Respondents were asked about their level of proficiency in use of information and communication technologies (ICTs). Among state actors, 33\% rated their ICT proficiency as sufficient; $57 \%$ as basic; and $10 \%$ insufficient. For private lawyers, $85 \%$ of private lawyers rated themselves as sufficiently IT proficient while $15 \%$ rated their proficiency with ICTs as basic. None of the private lawyers surveyed rated themselves insufficient in the use of ICTs. A big section of respondents from the public $(85 \%)$ said their knowledge of ICTs was insufficient, $5 \%$ sufficient and $10 \%$ basic.

\section{Information Management Practices.}

Ninety two (92\%) of state actors; $80 \%$ of members of the general public; and $90 \%$ of private lawyers viewed information sharing between institutions involved in case management as vital. State actors viewed information sharing as vital to increasing the rate of case completion leading to better service delivery (through improved collaboration and coordination). Members of the general public and private lawyers viewed information sharing as critical in improving the quality of investigations (between the Police and DPP); and an avenue for resolving cases faster (in the Judiciary). Therefore, there is need for a uniform information organization scheme for the JLOS institutions that will form the basis for information integration and sharing.

The next section presents requirements for developing usable integrated case management information systems.

\section{REQUIREMENTS FOR DEVELOPING USABLE INTEGRATED INFORMATION SYSTEMS}

This section presents requirements for developing usable integrated information systems based on the findings from the review of related literature and the survey.

\subsection{Information aggregation and presentation requirements.}

Integrated case management information systems should be able to provide a mechanism for providing appropriate presentation of processed data from various sources into well-aggregated facts for users to derive meaning and use as a basis for decision-making. Process managers and policy makers at the JLOS Secretariat (program coordination office) and in other management structures at institutional level require tools and interfaces to be able to access and manipulate the vast amounts of interconnected case data and visualize the outcome as a basis for decision making, formulation of policy direction, planning and strategy development. 


\subsection{User diversity (cognitive ability, physical capacity and technical proficiency) requirements.}

Unique characteristics of the diverse end-users in JLOS that impact on the overall usability of integrated information systems should be taken into account during the design process. These characteristics relate to user's cognitive ability (general appreciation and comprehension of subject matter, knowledge of the application domain and knowledge of the interface syntax/semantics); ICT proficiency; and physical state of the users. For example $33 \%$ of state actors rated their ICT proficiency as sufficient; $57 \%$ as basic; and $10 \%$ as insufficient. Eighty five (85) \% of private lawyers rated themselves as sufficiently IT proficient while $15 \%$ rated their knowledge of ICTs as basic. Additionally, the majority of those surveyed (90\%) viewed issues of physical disability as vital considerations during design and development of information systems (ergonomics).

\subsection{Information Organization Requirements.}

Information organization is the process of providing structure to information and definition of relationships between information items and groups [13]. An average of $81 \%$ of respondents (65\% in the Police; $85 \%$ in the DPP; $90 \%$ in the Judiciary; and $84 \%$ in the Prisons) said their institutions had some form of scheme for logically organizing information. However, only $18.5 \%$ of these respondents believed their inhouse schemes for structuring information are satisfactory and aligned to case management business processes. Lack of a uniform case identification scheme used by all the four institutions for processing cases in the criminal justice system was identified as a major information organization challenge. Therefore, there is need to provide useful and creative ways of sorting and organizing (structuring) information through an enterprise information architecture.

\subsection{Information Sharing Requirements.}

Information sharing is the process of exchanging of information assets between people and agencies. Ninety two (92\%) of state actors, $80 \%$ of members of the general public, and $90 \%$ of private counsels viewed information sharing between institutions involved in case management as vital. State actors associated information sharing to increasing the rate of completion of the case management process leading to better service delivery (through improved collaboration and coordination). Members of the general public and private counsel viewed information sharing as critical in improving the quality of investigations (between the Police and DPP); and as an avenue for resolving cases faster (in the Judiciary). Therefore, the model should support the discovery of information and collaboration between users in the different JLOS institutions through information sharing.

\subsection{Need to cater for the evolving nature of Information Systems.}

Seventy-five $(75 \%)$ of state actors surveyed during the survey identified the chang- 
ing nature of information systems in the Sector as a major challenge to sustainable usability. Changes in user needs, introduction of new processes (and business rules), introduction of new technologies et cetera often call for re-engineering of the existing systems. This creates challenges of balancing usability and functionality - with the former being often sacrificed at the expense of the latter. The requirement to address this scenario is to ensure that usability of the systems is synchronized with the changing nature of the business environment and technology. That is there should be proper integration of usability aspects in the overall design process during changes in business vision and transitions.

\subsection{Harmonize technologies used.}

The four (4) institutions surveyed operate and maintain different types of case management information systems each tailored to the agency's mandate and information needs. Additionally, this problem is also faced in some individual institutions such as judiciary that has different versions of the Court Case Management System running in different courts. The diverse nature of different (and in some instances legacy) technology platforms currently in use presents interoperability challenges in the integration effort. There is therefore need to harmonize hardware and software platforms across the JLOS institutions involved in criminal justice case management.

\subsection{Process efficiency requirements.}

The primary interest of case management is how information on file is leveraged in solving the case at hand. State actors were asked to rate the service turn around for their respective case management systems. Process completion rates in the Uganda Police were rated at an average of two to three (2-3) days; two (2) days for the DPP; three (3) days for Judiciary, and one (1) day for the Uganda Prisons. Ninety (90\%) of public officials attributed the slow case management process to poorly designed business processes; and 10\% attributed this challenge to entrenched institutional bureaucratic tendencies. There is therefore need to reengineer case management processes in the criminal justice system through a comprehensive business process review that ensures that only relevant tasks and procedures are maintained and supported by technology.

In summary, the requirements for developing usable integrated information systems as established from the review of related literature and a survey are: Information aggregation and presentation requirements; User diversity (cognitive ability, physical capacity and technical proficiency) requirements; Information Organization Requirements; Information Sharing Requirements; Need to cater for the evolving nature of Information Systems; Standardizing technologies used; and Process efficiency requirements.

The next section, discusses a model for developing usable integrated case management information systems. 


\section{DESIGN OF THE MODEL FOR DEVELOPING USABLE INTEGRATED CASE MANAGEMENT INFORMATION SYSTEMS}

\subsection{Introduction}

The model for developing usable integrated case management information systems is composed of a combination of design aspects derived from three (3) models that meet the requirements for the development of usable integrated information systems. The Architecture Development Method (ADM) provides a step-by-step guideline for architecture development and is, to considerable extent designed to deal with most system and organizational requirements from a functionality and usability point of view [18]. LUCID/Star* Model provides the core building blocks for user centered design that are represented in four stages of analyze, design, implement and evaluate [9]. The Model-based Framework for the Integration of Usability and Software Engineering Lifecycles provides development infrastructure in which the usability engineering and software engineering life cycles co-exist in complimentary roles [15].

\subsection{Description of the Model}

This section discusses a model for the design of usable integrated information systems known as the Architecture-driven Usability Process Model (AdUPRO) based on the requirements for developing usable integrated information systems discussed in Section Four (4). AdUPRO is composed of three modules: the enterprise architecture module, the interaction module and the Module Alignment Process (MAPs).

The "enterprise architecture module" provides a shared and enterprise approach to design, a common language for the realization of the shared design, a framework for requirements gathering and creation of a mutual understanding between how users, business and technology should integrate and mutually evolve over the course of time.

The "interaction module" provides an approach to user-centered design and incorporation of various usability aspects in the systems design process. The interaction design module is based on the LUCID/Star* process model.

The Module Alignment Process (MAPs) links the architecture and interaction modules into mutually existent, complimentary and integrated (but independent) components.

Figure 1 is a detailed illustration of the three modules of the architecture-driven usability process model - the architecture module, the interaction module and the module alignment process - as well as the illustration of each module's components, subcomponents and activities.

The enterprise architecture module (components $1.1-1.4$ ) represents a systematic involvement of stakeholders in the design process of integrated case management information systems by providing a coordinated vision of the enterprise's strategic direction, business practices, information flows and structure, and technology resources. The "architecture" of a typical information system is further a blueprint for the business process (business architecture), data structures (data architecture), busi- 
ness applications (applications architecture) and the interrelationships between these layers [1]. Activities under the architecture module provide the basis for understanding the "big picture" of the integrated case management information system and fulfilling requirements related to information sharing, information discovery, information organization, process reengineering, standardization of technology platforms and data formats. These requirements are fulfilled through: a critical appreciation of the enterprise architecture scope and definition of the design roadmap (Foundations architecture); a comprehensive understanding of users and the information environment and business context that they operate in (business architecture); an understanding of the user applications for processing and presenting business data (IS architecture) and proper alignment of technology to end user needs and requirements to enhance the user experience (technology architecture).

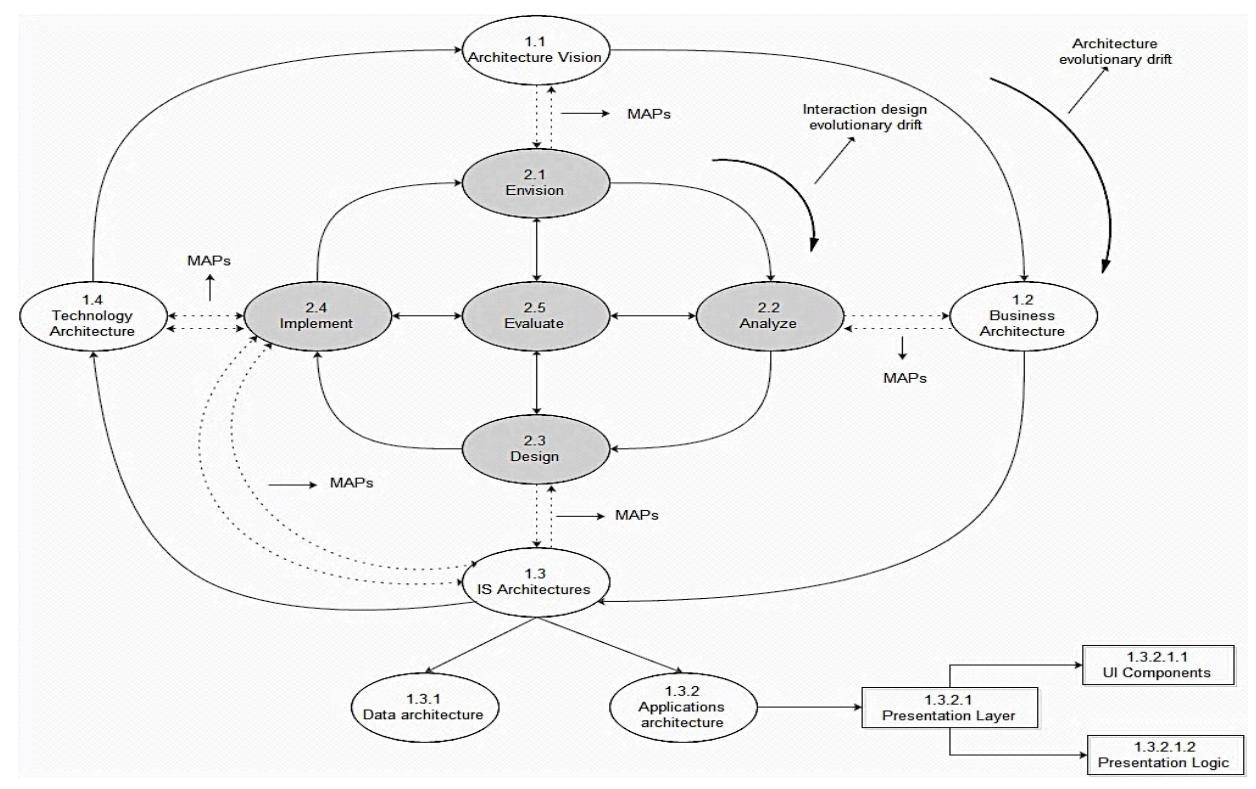

Fig. 1. Architecture-driven usability engineering process model

The goal of the interaction module (components $2.1-2.5$ ) is to develop an interactive integrated information system that is aligned to the user's unique environment, contexts and way of work [2] and responsive to how people (users) connect/interact with others to perform collaborative tasks and exchange (share) information $[16,17]$. To enhance the user experience with the integrated information systems, the interaction module supports intuitive navigation and content search mechanisms at the user interface (UI) level thereby enhancing users' ability to find information. This attribute contributes to fulfillment of information sharing requirements that address challenges experienced by users to find information that spans organizational boundaries, as is the case in the Justice, Law and Order Sector. 
The Module Alignment Process (MAPs) illustrates sharing/coordination of activities, iterations, timelines, techniques, artifacts and mappings between the enterprise architecture and interaction modules. According to Pyla et al [15], this referred to as "module activity awareness". MAPs, further illustrated in Figure 2 supports coordination of schedules and specification of activities and components in the interaction and enterprise architecture modules that have commonalities. For such activities, MAPs is able to indicate where and when those activities should be performed, who the involved stakeholders are, and communicates this information to both the architects and interaction designers. MAPs therefore provides a synchronized mapping of activities in the enterprise architecture and interaction modules through a link (alignment process) that ensures proper conceptualization of the integrated information environment and representation of usability aspects in integrated information systems.

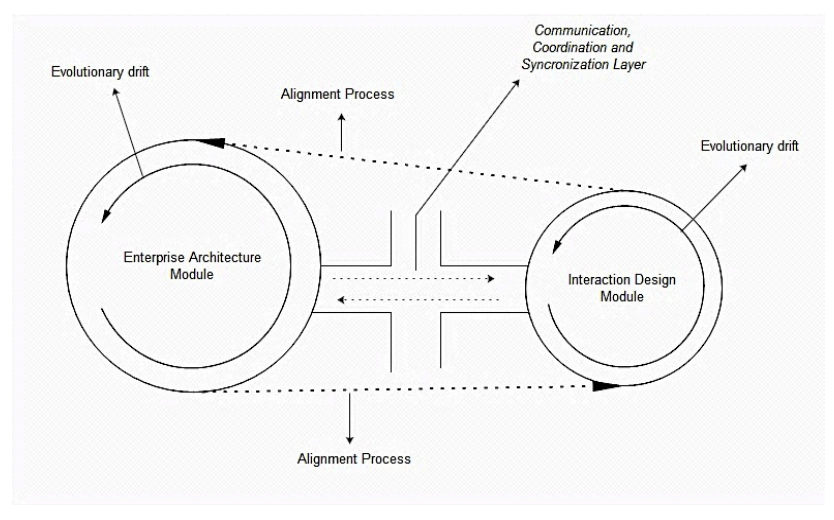

Fig. 2. Illustration of the Module Alignment Process (MAPs)

The "evolution drifts" represent the evolving nature of the integrated information system. These changes to both the architecture and interaction modules are illustrated by the architecture and interaction evolution drifts respectively. During the design process, the architectural models tend to appear too high level and too simple to adequately be aligned with certain design realities such as new and emerging user requirements. Secondly, changes in the enterprise (business, technology and user environment) are likely to trigger changes in the overall architecture of the integrated information system. This implies that a dynamic organizational environment requires a dynamic architecture that evolves and aligns itself to new and emerging parameters of the users (usability requirements), business and technology. The Architecture Development Method (ADM) supports this required flexibility. Relatedly, the interaction design activities should be synchronized with the changes in the architecture to reflect the most current shared vision and concept of the integrated information system. A communication, coordination and synchronization layer provides connectivity between the modules to implement this "alignment" process. 


\section{CONCLUSION AND FUTURE WORK}

This study was an attempt to develop a model that significantly incorporates human factors in the development of integrated case management information systems. The study was further focused on addressing design-reality gaps represented by usability dimensions in integrated e-justice projects in Uganda's Justice, Law and Order Sector - specifically in criminal justice institutions. These design reality gaps relate to the usability dimensions of information, technology, processes, objectives and values, skills and knowledge, management systems and structures, and other resources. Review of literature and a research survey were conducted to provide information on the extent of the problem and other usability issues encountered in integrated information systems. Findings from this survey provided the basis for the development of requirements and design decisions to address the identified issues, problems and usability gaps. To fulfill these requirements and design decisions, an artifact known as AdUPRO (Architecture-driven Usability Process Model) was developed to guide the development of a usable integrated information system.

AdUPRO to a great extent addresses the core problem of this study - how to develop usable integrated case management information systems. The model shows how requirements for usable integrated case management information systems can be achieved in the development of integrated information systems through its three modules. However, the model is still at the theoretical stage. Our next steps will be to validate the extent the model can effectively guide development of usable integrated information systems through development of a prototype integrated case management information system used by the Police, DPP, Judiciary and Uganda Prisons Service.

For purposes of future research, the recommendation is that the model should systematically and specifically address psychodynamic factors (unconscious aspects of human behavior) and their implications on the usability of integrated information systems.

\section{ACKNOWLEDGEMENTS}

We are grateful to the Justice, Law and Order Sector (JLOS) Secretariat (Ministry of Justice and Constitutional Affairs, Government of Uganda) and all participants in the study from the general public, legal fraternity (Uganda Law Society), the Judiciary, Uganda Police, the Directorate of Public Prosecutions and the Uganda Prisons Service. 


\section{REFERENCES}

1. Arnold, B., Op't Land, M. and Dietz, J. (2002). Effects of an Architecture Approach to the Implementation of Shared Service Centres. Conference Paper for the Dutch National Architecture Congress in 2002.

2. Benyon, D., Turner, P., and Turner, S. (2005). Designing Interactive Systems: People, Activities, Contexts, Technologies, ISBN-13: 978-0321116291

3. Bradley, R., Pridmore, J.L. and Bryrd, T.A. (2006). Information Systems Success in the Context of Different Corporate Cultural Types: an Empirical Investigation, Journal of Management Information Systems, Vol. 33, No. 2, pp. 267-294, 2006.

4. Card, K. S., Mackinlay, J. D., and Shneiderman, B. (1999). Readings in Information Visualization, using vision to think. Morgan Kaufmann, Cal. USA.

5. Dykes, J. A., MacEachren, A. M., \& Kraak, M.-J., eds. (2005): Exploring Geovisualization, Amsterdam: Elsevier, 710 pp.

6. Gabbard, J.L, Hix, D., Swan, E., Livingston, M.A., Hollerer, T.H., Julier, S.J., Brown, D., and Baillot, Y. (2003). Usability Engineering for Complex Interactive Systems Development. Proceedings of Human Systems Integration Symposium 2003., Engineering for Usability, Vienna, VA. June 23-25, 2003

7. Gould, J.D and Lewis, C. (1985). Designing for Usability: Key Principles and What Designers Think. Communications of the ACM, March, Vol. 28, No. 3, 300-311

8. Heeks, R. (2001): Understanding e-Governance for Development, I-Government Working Paper Series, Paper No. 11, Institute for Development Policy and Management

9. Helms, J.W (2001): Developing and Evaluating the (LUCID/Star)*Usability Engineering Process Model, Thesis submitted to the Faculty of the Virginia Polytechnic Institute and State University

10. Integrated Justice Information Management Systems Project Plan (2012). The Justice, Law and Order Sector. Government of the Republic of Uganda

11. International Standards Organization (ISO 9241-210:2010): Ergonomics of Human System Interaction - Part 210: Human-centered Design for Interactive Systems

12. Lederer, A.L and Prasad, J. (1992). Nine Management Guidelines for Better Cost Estimating. Communications of the ACM, Vol. 35, Issue 2,February 1992. Pp. 51-59

13. Morville, P. and Rosenfeld, L. (2006). Information Architecture for the World Wide Web, $3^{\text {rd }}$ Edition. O'Reilly Media.

14. Pitula, K., Sinning, D., and Radhakrishnan, T. (2015): Making Technology Fit: Designing an Information Management System for Monitoring Social Protection Programmes in St. Kitts, URL: http://sta.uwi.edu/conferences/09/salises/documents/D\%20Dysart-Gale.pdf (Retrieved on February 27 2017)

15. Pyla, P.S, Pérez-Quiñones, M.A, Arthur and J.D, Hartson, H.R (2003). Towards a Modelbased Framework for Integrating Usability and Software Engineering Life Cycles. In: Interact 2003 Workshop on Closing the Gaps: Software Engineering and Human Computer Interaction. 2003: Universite catholigue da Louvain, Institut d 'Administration et de Gestion (IAG) on behalf of the International Federation of Information Processing (IFIP), pp. 67-74

16. Saffer, D. (2009). Designing for Interaction: Creating Innovative Applications and Devices (2nd Edition) (Voices That Matter). New Riders, Berkerly, CA.

17. Sharp, H., Rogers, Y., and Preece, J. (2007). Interaction Design: Beyond HumanComputer Interaction, John Wiley \& Sons, England.

18. The open Group Architecture Forum (TOGAF) (2009): The Open Group Architecture Framework Version 9. Van Haren Publishing, Zaltbommel. 